\title{
A Reply to Dutton's (2013) Comment
}

\author{
Gerhard Meisenberg ${ }^{1}$ \\ Ross University School of Medicine, Portsmouth, Domínica
}

This brief report is a reply to Dutton, E. (2013). A Problematic Proxy? On Meisenberg, Rindermann, Patel and Woodley's (2012) analysis of the relationship between religiosity and intelligence within countries. Temas em Psicologia, 21(2), 525-527.

The comment by Edward Dutton (2013) raises some interesting questions. Most of the uncertainty is found at the ends of the developmental spectrum: societies before the advent of modernity, and those that are most advanced. At the lower end, the question is: Is "primitive man" steeped in religious beliefs that are held with great conviction, or is there a primordial state of "primitive agnosticism" in which contradictory opinions about the spirit world, magic, sorcery and afterlife coexist in the same community and even the same person? A certain level of cognitive complexity and intellectual rigor seems to be required for well-formed, internally consistent belief systems.

Education is an imperfect measure of acculturation as well as of intelligence. Therefore I agree that a reason for apparent positive associations between religiosity and education in the least developed countries, especially in tropical Africa, most likely is the prevalence of "pre-religious" or "proto-religious" beliefs that are focused on magic and sorcery (e.g., Jahoda, 1970; Zusne \& Jones, 1989). There may even be a "mission school effect" caused by the role of Christian missionaries in the first beginnings of modern schooling in many African countries. At a certain level of cultural evolution, represented by Medieval Europe and by much of sub-Saharan Africa today, organized religion represents the worldview of the more educated and sophisticated sections of society while magic and sorcery are more influential among the unsophisticated. In Asian countries at this level of development we find both monotheistic religious beliefs (Hindu philosophy) and more-orless atheist philosophies (Buddhism, Confucianism, Taoism) among the traditionally educated, while either polytheism (India) or ritual based on ancient ancestor worship (East Asia) persisted among common people.

More important for our time is the question about the viability of religion at the highest levels of cognitive development. One question is: Are people becoming more intelligent during the $21^{\text {st }}$ century, or have we already reached the limits of our intellectual potential? Evidence shows that the rising intelligence trend ("Flynn effect") that was universal in Europe and East Asia during the $20^{\text {th }}$ century has ceased in these countries. Stagnation or even slow decline of intelligence is now observed among young adults, at least in the countries of northern Europe (Dutton \& Lynn, in press; Meisenberg \& Woodley, in press; Shayer \& Ginsburg, 2009; Teasdale $\&$ Owen, 2008). Therefore radically new developments in religion and society that are not predictable from observations in today's most advanced societies are unlikely. At the same time, continuing Flynn effects in less developed countries predict that $21^{\text {st-century developments }}$ in these countries will resemble to some extent the $20^{\text {th }}$-century developments in more advanced societies (Meisenberg \& Woodley, in press).

In addition to influences of intelligence, education or rationality on religious trends, we

1 Endereço para correspondência: Ross University School of Medicine, Picard Estate, Portsmouth, Dominica. E-mail: gmeisenberg@rossmed.edu.dm 
should also consider the reverse: Which religions will provide the intellectual elites of the $21^{\text {st }}$ and $22^{\text {nd }}$ centuries? First, the universal negative relationship of fertility with education and intelligence in modern societies (Meisenberg, 2008; Skirbekk, 2008) guarantees a slow but persistent downward trend of intelligence after the end of the Flynn effect. Traditional religion will survive in part because of lower intelligence, and in part because highly religious people have higher fertility than atheists, especially but not only in countries in which less educated people tend to be more religious (Meisenberg, 2012).

One remarkable modern trend is the decline of the "demythologized" Protestant religions of Europe and the liberal Protestant denominations of the Americas. Fundamentalist Protestants and Mormons are thriving, despite science-denying beliefs and, in the Mormon case, a religious historiography of the New World that is incompatible with scientific evidence. Even more surprising is that among Mormons, at least, educational levels are above average (Goodman \& Heaton, 1986), the relationship between religious involvement and education is strongly positive, and there appears to be no negative relationship between fertility and education even for women (Heaton, 1994). I agree with Dutton (2013) that much of this can be explained by high conscientiousness favoring education, religion and, among Mormons at least, family life and high fertility. Or is perhaps the "clever sillies" hypothesis (Woodley, 2010) part of the explanation? Perhaps some of the most "irrational" religions can thrive by converting and retaining selectively those who are intelligent enough to reason away the religion's contradictions. If this is the case, not only religion but also high intelligence may survive after all - but only in these religious groups.

\section{References}

Dutton, E. (2013). A Problematic Proxy? On Meisenberg, Rindermann, Patel and Woodley (2012). Analysis of the Relationship between Religiosity and Intelligence within Countries. Temas em Psicologia, 21(2), 525-527. doi: DOI: 10.9788/ TP2013.2-18.
Dutton, E., \& Lynn, R. (in press). A negative Flynn effect in Finland, 1997-2009. Intelligence.

Goodman, K. L., \& Heaton, T. B. (1986). LDS church members in the U.S. and Canada: A demographic profile. AMCAP Journal, 12, 88-107.

Heaton, T. B. (1994). Familial, socioeconomic, and religious behavior: A comparison of LDS and non-LDS women. Dialogue, 27, 169-183.

Jahoda, G. (1970). Supernatural beliefs and changing cognitive structures among Ghanaian university students. Journal of Cross-Cultural Psychology, $1,115-130$

Meisenberg, G. (2008). How universal is the negative correlation between education and fertility? Journal of Social Political and Economic Studies, 33, 205-227.

Meisenberg, G. (2012). Demography and modernization as the major determinants of religious belief. Mankind Quarterly, 52, 388-414.

Meisenberg, G., \& Woodley, M. A. (in press). Are cognitive differences between countries diminishing? Evidence from TIMSS and PISA. Intelligence.

Shayer, M., \& Ginsburg, D. (2009). Thirty years on - a large anti-Flynn effect? (II): 13- and 14-year olds. Piagetian tests of formal operations norms 1976-2006/7. British Journal of Educational Psychology, 79, 409-418.

Skirbekk, V. (2008). Fertility trends by social status. Demographic Research, 18(5), 145-180.

Teasdale, T. W., \& Owen, D. R. (2008). Secular declines in cognitive test scores: A reversal of the Flynn effect. Intelligence, 36, 121-126.

Woodley, M. A. (2010). Are high-IQ individuals deficient in common sense? A critical examination of the 'clever sillies' hypothesis. Intelligence, $38,471-480$.

Zusne, L., \& Jones, W. H. (1989). Anomalistic Psychology. A Study of Magical Thinking ( $2^{\text {nd }}$ ed.). Hillsdale, NJ: Erlbaum. 